\title{
CONFERENCE-REPORT
}

\section{Responsibility and Authority in Drinking: Arctic Workshop at the University of Tartu, Estonia (30-31 May 2014)}

This 2014 workshop was the fifth Arctic workshop held at the University of Tartu and the second dedicated to alcohol. In retrospect, both workshops were fruitful but differed in scope. The main difference between the first workshop in 2013 and second was that the first focused primarily on the social and cultural meaning of alcohol in the Arctic and the second broadened its geography. In the latter, we included papers presenting research results from outside the Arctic region. Comparing two workshops, then, it should be mentioned that, while the first was more in-depth, the second had more comparative focus. Besides various regions of Siberia, the talks in the workshop dealt with Mongolia, Latvia, and Sweden. Unfortunately, several participants had to cancel at the last moment-therefore an exciting study about alcohol use among Ethiopian students and the semantics of Canadian alcoholism were missed.

In retrospect, it seems that talks about different roles and meanings of alcohol in relation to religion dominated the workshop. The papers presented by Tatiana Bulgakova (Herzen State Pedagogical University in St. Petersburg) and Laurent Legrain (Université Libre de Bruxelles) had the same topic: the role of alcohol in shamanism. In both cases, shamans seemed to have controversial relationships with drinking. In Nanai and Mongolian cultures, vodka is a traditional drink when celebrating but also remains a symbol for outside cultural intervention. In a similar way, alcohol is embedded in everyday behavior and ceremonies, but its use is condemned by people at the same time. However, in the Mongolian case, vodka seems to be more a legitimate substance in rituals. Legrain introduced the expression of "moral drinking" meaning that certain rituals — especially singing-are related to alcohol because alcohol consumption is always present in such cases. Children see parents drunk and singing, and therefore they relate singing with alcohol. In such a way, alcohol consumption attains certain ritualistic colors. During the last workshop, Eleanor Peers (University of Aberdeen) presented on the controversies regarding drinking in Sakha culture. According to her presentation, the mid-summer celebration Ysyakh is kept alcohol-free, giving this abstinence a political meaning. Non-drinking in modern Sakha culture is related with pre-Russian 
tradition, maintaining the nation's health and respect for cultural roots. Simultaneously, heavy drinking is still a sign of masculinity for young Sakha men, especially those in villages. As a result, drinking causes conflicts, and in order to avoid these conflicts, alcohol consumption is spatially separated from the public and ritual sites in Ysyakh.

Masculinity and ritualistic drinking seems to be another focus of interest among researchers. Vieda Skultans (University of Bristol) argues that a certain "alcohol belt" exists from Siberia to Scandinavia, where alcohol consumption is accompanied by similar attitudes and rituals. Indeed, the perception that "it is not shameful to fall down, but it is a shame not to get up" when drunk probably applies to this whole "belt". Elianne Anemaat (University of Amsterdam) added to that discussion a perspective on how the state copes with alcohol-related masculinities. Scandinavians are, maybe unjustly, notorious for heavy binge drinking. First of all, in order to reduce alcohol consumption, the Swedish state tried to introduce the concept of "continental drinking"; in other words, they aimed to promote more controlled drinking where smaller quantities are consumed. It was interesting to hear that Swedes usually do not protest against the state but simultaneously maintain a certain equality in drinking - everybody must drink more or less on the same level. Anemaat explained that this ideology of equality itself was also introduced through state socialism.

Last but not least, other papers focused on the image of alcohol as a force majeure in Siberian indigenous communities. Kirill Istomin from the Komi Science Center in the Russian Academy of Sciences, Anastasia A. Yarzutkina from the Anadyr branch of the Russian Academy of Sciences, and Lyudmila N. Khakhovskaya of the Magadan branch showed how European Nenets, Chukchi, and Koriak people view alcohol as a force outside of their control. Alcoholism is seen by these groups as the interference of outside powers and something a person is unable to fight.

The final presentation was made by main discussant Nikolai Vakhtin (European University in St. Petersburg) who summed up the workshop's presentation and discussion topics. First of all, he emphasized that alcohol is very deeply embedded in everyday social life all over the northern hemisphere, independent of the ethnic background (This was also one of the commonly agreed results of the first alcohol workshop.) Drinking together expresses group solidarity and makes people socially closer. On the other hand, the definition of what counts as drinking is ambivalent. Socially accepted drinking occurs mainly in groups and often outside the home, in bars, or during celebrations. 
Interestingly, hard-working men and other "useful people" are allowed to drink while people from less physical occupations should not drink heavily. Moreover, marginal groups are "licensed to drink", but there a question arises: do these people drink because they are marginal or are they marginal because they drink? In general, the European idea for coping with "evil drinking" is to ignore it (Latvian case), while the Scandinavian approach is to fight it. Simultaneously, Vakhtin argued that we do not have clear analytical concepts to deal with these issues. Vakhtin also questioned why drinking is related so strongly to masculinity. As it stands, we really do not know whose idea that is nor from whence it originates. There were also some optimistic notes in the final presentation: drinking in groups means a lack of obligation and temporary freedom in a situation where all are equal.

The workshop was interesting and productive. As always, the participants agreed that there were more topics to discuss than could have been covered in only two days. Drinking is a complicated thing: it is a web of social relations and cultural concepts linking the individual, different social groups, society, and state. And so, our final quote from Vakhtin states: "Let's imagine: how would the world be without alcohol? How would our society function and exist?"

\author{
Aimar Ventsel \\ University of Tartu, Estonia
}

